\title{
La educación en Cuba a la luz de los derechos fundamentales
}

\section{Education in Cuba in the Light of Fundamental Rights}

\begin{abstract}
RESUMEN: La configuración constitucional y legal de la educación en Cuba, a partir de su prestación exclusiva y excluyente por el Estado, y de lo incontrovertible de las decisiones administrativas en esta materia, se orienta más a una función pública soberana del Estado que a un servicio público en el sentido técnico jurídico del término. La falta de garantías, como la eficacia directa y vinculación de todos los "poderes" públicos, la reserva de ley, la indisponibilidad legislativa para la regresión, el contenido esencial o mínimo intocable, y la tutela judicial efectiva, constituyen serias limitaciones para considerar la educación en Cuba como un derecho fundamental, a la luz de esta teoría. Esta situación legislativa puede ubicar a los titulares del derecho en posiciones de desprotección ante posibles vulneraciones emanadas de arbitrariedades administrativas o de retrocesos legislativos. Palabras clave: educación, derecho fundamental, garantías, servicio público.
\end{abstract}

\section{Alie PÉREZ VÉLIZ*}

ABSTRACT: The constitutional and legal configuration of education in Cuba, being exclusively provided by the State, and with the incontrovertible administrative decisions in this matter, is more oriented to a sovereign public function of the State than to a public service in the legal sense of the term. The lack of guarantees, such as the direct effectiveness and binding of all public "powers", the reservation of law, the legislative unavailability for regression, the essential or minimum untouchable content, and effective judicial protection, constitute serious limitations to consider the education in Cuba as a fundamental right, in light of this theory. This legislative situation can place the holders of the right in positions of vulnerability to possible violations arising from administrative arbitrariness or legislative setbacks.

Key words: Education, Fundamental Rights, Guarantees, Public Service.

* Profesor titular de la Universidad de Pinar del Río "Hermanos Saíz Montes de Oca”, doctor en ciencias. Contacto: alieperez1977@gmail.com y alievez@upr.edu.cu, ORCID: 0000-0002-5097-8520. 
SUMARIO: I. Introducción. II. La educación en Cuba como servicio público: consideraciones críticas. III. La educación en Cuba: principales limitaciones a la luz de la teoría de los derechos fundamentales. IV. La educación en Cuba y el cumplimiento de los requisitos de fundamentalidad. V. Conclusiones.

VI. Bibliografía.

\section{INTRODUCCIÓN}

La actividad de prestación o servicio público es relativamente reciente, data del siglo XIX en sus formas actuales, en que los Estados comenzaron a asumir actividades que eran realizadas hasta ese momento por otros sujetos. La Iglesia Católica, por ejemplo, se había ocupado de la enseñanza en seminarios y escuelas parroquiales, como parte de su labor misionera, desde finales del Medioevo. Otros servicios, como el de postas (correos), habían aparecido en siglos anteriores, en época de las monarquías absolutas y asociados a la formación de los Estados nacionales.

Estas formas prestacionales, como el ya referido servicio de postas, la administración de justicia, la defensa y las relaciones exteriores, estaban más orientadas a garantizar las necesidades abstractas de la nueva comunidad política, que dirigidas a proporcionar utilidad a personas concretas. ${ }^{1}$ Respondían, con mayor vocación, a las necesidades de los nacientes Estados, de sus aparatos de poder, que a la de los propios administrados.

En este contexto resulta imposible pensar en la preocupación de la administración por responder a exigencias de calidad y cantidad en los servicios, por parte de los administrados, quienes se suponen los principales destinatarios. En este sentido, más que un servicio público se trataba de una actuación del Estado para garantizar su capacidad de organización y control: era una actividad de policía transfigurada en formas prestacionales.

La doctrina italiana hace una distinción interesante entre servicio y función públicos soberanos del Estado. ${ }^{2}$ El primero es una actividad al margen de la noción de soberanía, posibilitando la simultánea realización

1 Santamaría Pastor, Juan Alfonso, Principios de derecho administrativo general II, Madrid, Iustel, 2009, p. 303.

2 Fundamentalmente, autores como Santi Romano y Vittorio Enmanuele Orlando en sus posturas institucionalistas sobre el Estado como soberano.

Esta obra está bajo una Licencia Creative Commons

Atribución-NoComercial-SinDerivar 4.0 Internacional, IIJ-UNAM. 
de la actividad por los particulares, donde no es exclusiva la actuación estatal. La función pública soberana, por su parte, sí implica actuación estatal soberana, en régimen estatal exclusivo, y sin ninguna posibilidad de intervención privada.

Parecería en este caso que existe cierta redundancia en el empleo de los términos público y soberano; pero en realidad aluden a dos cualidades diferentes de la actividad estatal a la que se les atribuye: lo público indica su orientación a satisfacer un interés estatal que llega o afecta de alguna manera a todos, o cuyos efectos son generales; y lo soberano indica el carácter exclusivo de la actuación estatal, sin posibilidad de interferencia, por alguien ajeno al Estado o a sus dependencias administrativas.

De asumirse la referida doctrina italiana, la actividad educacional en Cuba, más que un servicio público, es una función pública soberana del Estado. Esto es así, desde la promulgación de la Ley de Nacionalización General y Gratuita de la Enseñanza, del 6 de junio de 1961 (sin número) y que expone: "La función de la enseñanza es un deber a cargo del Estado Revolucionario que éste no debe delegar ni transferir". ${ }^{3}$ Dicha Ley dispone en su artículo número uno: "Se declara pública la función de la enseñanza y gratuita su prestación. Corresponde al Estado ejercer dicha función a través de los organismos creados al efecto...". ${ }^{4}$

En el siguiente artículo se dispone la nacionalización y adjudicación a favor del Estado cubano de todos los centros de enseñanza, sean operados por personas naturales o jurídicas privadas; así como la totalidad de los bienes, derechos y acciones que integran el patrimonio de los centros citados en la referida legislación. Esto supone una exclusividad estatal en régimen de monopolio por parte del Estado que implica necesariamente actuación estatal soberana, tal como refiere la doctrina expuesta. ${ }^{5}$ La actividad prestacional regulada por ésta se enfoca más a un uti universi que a un uti singuli.

Sin embargo, el propio Ramón Parada ${ }^{6}$ refiere que es difícil mantener la posición de la doctrina italiana en la actualidad, donde se torna invisible la frontera que separa la actividad de prestación o servicio público

3 Bell Lara, José et al., Documentos de la Revolución Cubana 1961, La Habana, Editorial de Ciencias Sociales, 2008, p. 145.

4 Ibidem, p. 146.

5 Parada Vázquez, Ramón, Derecho administrativo I, parte general, Madrid, Marcial Pons, Ediciones Jurídicas, 1991, p. 420.

6 Idem. 
de la actividad privada. Se señala que dentro del propio liberalismo una actividad ha transitado del sector público al privado y ha regresado al público, en dependencia de la tendencia de la misma a generar ganancias. Indica que en el "régimen" socialista ocurre lo contrario, las actividades que comportan poder, ganancias financieras y el dominio sobre los grandes medios de producción, tienden a ser controladas por el sector público, dejando el resto para el sector privado.

A lo anterior hay que señalar que, en determinados contextos, donde ciertos servicios garantizan el control ideológico sobre grandes masas de la población, así como un capital político excepcional, dichos servicios suelen pasar a ser una función pública soberana del Estado, presentados como conquista social, con todas las consecuencias positivas y negativas que ello acarrea: cobertura universal, elevado costo público y progresivo deterioro en la calidad del servicio, entre otros. En las experiencias del llamado socialismo real, la salud y la educación son ejemplos paradigmáticos.

Esta postura relativa a los llamados derechos de prestación, derechos económicos, sociales y culturales, o derechos humanos tiene especial trascendencia para el derecho administrativo y el derecho constitucional. Los diseños de dichos servicios, en la mayoría de las experiencias socialistas, se han caracterizado por una elevada intervención del Estado, con dominio exclusivo o cuasi exclusivo de las actividades prestacionales tendentes a garantizar los derechos sociales.

Esta realidad legislativa incluye, sin embargo, significativas paradojas: se constitucionalizan estos derechos como fundamentales, se excluye la propiedad privada y la gestión privada sobre la actividad y los bienes que la soportan, se fortalecen las competencias administrativas hasta niveles casi arbitrarios; por otro lado, se excluye la tutela judicial efectiva de dichos derechos, haciendo incontrovertible la calidad de la prestación por vía judicial; además, desde el punto de vista del derecho laboral, se mantiene sobre los agentes que prestan los servicios un régimen disciplinario rígido, y un régimen salarial deprimido.

Las señaladas características en materia de derechos laborales son especialmente apreciables en condiciones de crisis económica, donde el empeño por mantener el servicio a cualquier costo, como garantía legitimadora del sistema político, se hace recaer directamente sobre los trabajadores que lo garantizan, a través del deterioro de sus garantías laborales; e indirec- 
tamente sobre los usuarios, a través del deterioro progresivo de la calidad en dicho servicio.

Es objetivo de este trabajo realizar una valoración de la educación en Cuba como servicio público; determinar las características que ésta ha tenido en los últimos cincuenta años para considerarla como tal; igualmente, el autor constatará si el servicio público educativo, si existiere en el contexto nacional, se articula coherentemente con el derecho fundamental a la educación. Pero estos objetivos no serán realizados de una manera declarativa, sino razonada, usando la ponderación cuando proceda, sin renunciar a la crítica; para ello se recurrirá al método histórico jurídico y al análisis jurídico doctrinal.

\section{LA EDUCACIÓN EN CUBA COMO SERVICIO PÚBLICO: CONSIDERACIONES CRÍTICAS}

Según Ramón Parada, la actividad administrativa de prestación es "aquella por la que la administración, sin limitar, ni incentivar la actividad privada, satisface directamente una necesidad pública mediante la prestación de un servicio a los administrados...". ${ }^{7}$ En seguida, dicho autor menciona, entre los servicios públicos que presta la administración, el de enseñanza.

La prestación o servicio público supone la existencia de una relación entre la administración y el administrado, pero no una relación administrativa cualquiera, sino una singular relación de prestación. La naturaleza de la relación jurídica prestacional es sustancialmente diferente a la relación jurídica de policía o a la relación jurídica de fomento. El fin de ellas es diferente: en las últimas se persigue la organización y el control necesarios a la convivencia social, o el estímulo al desarrollo de una actividad económica o social que la administración pública no está dispuesta a asumir.

Con relación a la prestación o servicio público, la administración, o su concesionario, son los sujetos prestadores del servicio, mientras que el particular que recibe el servicio es el beneficiario. Como refiere Parada Vázquez: "El primer aspecto relevante de la relación es el derecho del particular de ser admitido al disfrute del servicio, derecho subjetivo incuestionable si reúne las condiciones legalmente establecidas, como puede

\footnotetext{
7 Ibidem, p. 418.
} 
ser poseer determinados títulos para matricularse en un establecimiento universitario". 8

El derecho subjetivo supone una facultad de hacer, no hacer o exigir una acción u omisión de alguien. En el caso del servicio público de educación se trataría del derecho a exigir de la administración cualquier actuación dirigida al reconocimiento de dicho derecho. Pero el derecho subjetivo por sí mismo, incluso su aparición explícita en un enunciado normativo de la Constitución: no representa mucho sin sus respectivas garantías; éstas compulsan la materialización del derecho, vinculando a todos, principalmente a la administración pública, con la conducta debida.

El referido autor español expresa más adelante:

El carácter rigurosamente público de la relación de prestación lleva consigo la competencia de la jurisdicción contencioso-administrativa ante la que debe protegerse su efectividad en caso de que el usuario no fuere admitido al disfrute del servicio, o fuese rechazado una vez admitido, o tratado de forma indebida. ${ }^{9}$

Ante este planteamiento cabría preguntarse si la educación es un servicio público en Cuba, como supone el inciso "b" del artículo 39 de la Constitución de 1976, con las posteriores reformas, el que estipulaba que “...la enseñanza es función del Estado y es gratuita... la ley precisa la integración y estructura del sistema nacional de enseñanza, así como el alcance de la obligatoriedad de estudiar y define la preparación general básica que, como mínimo, debe adquirir todo ciudadano". ${ }^{10}$ Dicho artículo da continuidad al espíritu de la Ley de Nacionalización General y Gratuita de la Enseñanza de 1961.

La alusión constitucional a que la ley precisa la integración y estructura del sistema nacional de enseñanza ha sido interpretada en dos sentidos: uno estricto y formal, en que se ha entendido que el constituyente mandata a la Asamblea Nacional del Poder Popular para que regule la actividad educacional; y en un sentido amplio y material, que expresa una autorización a quien proceda para crear disposiciones normativas de cualquier rango, dirigidas a regular dicha actividad.

8 Ibidem, p. 428.

9 Ibidem, p. 429.

10 Constitución de la República de Cuba, La Habana, Dirección de Legislación y Asesoría MINJUS, 2005, p. 32.

Esta obra está bajo una Licencia Creative Commons

Atribución-NoComercial-SinDerivar 4.0 Internacional, IIJ-UNAM. 
Si se asumiera la primera interpretación, el ordenamiento jurídico cubano estaría ante un vacío legal, pues la referida Asamblea no ha promulgado, desde su Constitución en 1976, ninguna ley que regule de modo general el sistema nacional de educación, lo cual daría paso a lo que Jesús María Casal ${ }^{11}$ y ciertos ordenamientos jurídicos (Portugal y Brasil, entre otros) califican como inconstitucionalidad por omisión legislativa. Para acoger esta interpretación, habría que asumir el carácter autoaplicativo de la Constitución cubana, algo cuya falta de concreción está fuera de discusión, por lo menos, en la práctica judicial de los últimos cincuenta años.

Una comprensión sistemática del ordenamiento jurídico cubano y de su tradición legislativa, donde no existe la reserva de ley, hace suponer que el "Constituyente" se refiere al segundo sentido de la expresión. Esto es lo que ha acontecido en la práctica desde 1976. Las regulaciones sobre el servicio público educativo, desde la referida fecha, se han introducido en Cuba vía acuerdos del Consejo de Ministros, su Comité Ejecutivo, y de resoluciones del Ministerio de Educación, como ente a la vez regulador y prestador del servicio; por mandato de los decretos-ley núm. 67 de 1983 y núm. 147 de 1994, de organización y reorganización de los Organismos de la Administración Central del Estado.

Pero hay otro elemento a valorar en la realidad cubana, que complica la consideración de la educación como prestación o servicio público, por lo menos en el sentido que lo define Parada Vázquez. El artículo 657 de la Ley núm. 7, del Procedimiento Civil, Administrativo y Laboral de 1977, prohíbe expresamente la tutela judicial efectiva, por vía contenciosa, para cualquier asunto que suscite conflicto en materia de actividad educativa.

El apartado quinto del mencionado artículo dispone: "No corresponden a la jurisdicción administrativa las cuestiones que se susciten con relación a las disposiciones que emanen de una autoridad competente concernientes a: ...5. La actividad educacional y la disciplina escolar y estudiantil...". ${ }^{2}$ Esto aparta a Cuba de la legislación y la doctrina predominantes en el derecho administrativo hispanoamericano, y enfatiza el carácter singular del ordenamiento jurídico cubano, donde las facultades domíni-

11 Casal, Jesús María, Constitución y justicia constitucional, Los fundamentos de la justicia constitucional en la nueva carta magna, Caracas, Publicaciones UCAB, 2000, p. 184.

12 Ley núm. 7 de Procedimiento Civil, Administrativo y Laboral, del 19 de agosto de 1977, Villa Clara, EGVC, p. 79. 
cas de la administración pública en sectores estratégicos para el país son incontrovertibles, al menos en sede judicial.

Es evidente, como plantea Parada Vázquez, que no hay actividades públicas o privadas por naturaleza, sino que tal ubicación depende en cada caso y circunstancia de lo que decida el poder político. ${ }^{13}$ En Cuba, desde 1961 el Estado reservó a la administración pública, con carácter exclusivo, la enseñanza; lo consagró a nivel constitucional desde 1976, y lo convirtió por la Ley procesal de 1977, como se ha dicho, en un asunto no sujeto a controversias por vía judicial.

La nueva Constitución de la República de Cuba, proclamada el 10 de abril de 2019, no parece haber cambiado sustancialmente la naturaleza jurídica de la educación como función soberana del Estado. El artículo 32, inciso " $b$ " de dicho cuerpo normativo dispone: "la enseñanza es función del Estado, es laica y se basa en los aportes de la ciencia y en los principios y valores de nuestra sociedad". ${ }^{14}$

Sin embargo, el propio texto parece ampliar el amparo constitucional a la educación cuando la configura como un derecho en el artículo 73: "La educación es un derecho de todas las personas y responsabilidad del Estado, que garantiza servicios de educación gratuitos, asequibles y de calidad para la formación integral, desde la primera infancia hasta la enseñanza universitaria de postgrado". ${ }^{15}$ Por primera vez, parece ampararse el derecho a una educación de calidad, particularizando en la dimensión cualitativa de la misma, lo cual constituye un avance en materia de derechos fundamentales, a tono con la doctrina y la práctica jurisdiccional extranjera.

No obstante lo anterior, en la recién aprobada Constitución no se especifica de manera amplia las garantías materiales a ese derecho, como sí hacía la Constitución de 1976 reformada, la que especificaba en su artículo 51:

...este derecho está garantizado por el amplio y gratuito sistema de escuelas, seminternados, internados y becas, en todos los tipos y niveles de enseñanza, y por la gratuidad del material escolar, lo que proporciona a cada niño y joven, cualquiera que sea la situación económica de su familia, la oportunidad

13 Parada Vázquez, Ramón, Derecho administrativo I, parte general, Madrid, Marcial Pons, Ediciones Jurídicas, 1991, p. 422.

14 Constitución de la República de Cuba, La Habana, Editora Política, 2019, p. 12.

15 Ibidem, p. 21. 
de cursar estudios de acuerdo con sus aptitudes, las exigencias sociales y las necesidades del desarrollo económico-social. ${ }^{16}$

Por su parte, la actual carta magna, plantea:

El Estado, para hacer efectivo este derecho, establece un amplio sistema de instituciones educacionales en todos los tipos y niveles educativos, que brinda la posibilidad de estudiar en cualquier etapa de la vida de acuerdo con las aptitudes, las exigencias sociales y a las necesidades del desarrollo económico-social. ${ }^{17}$

Comparativamente ambas disposiciones constitucionales son similares, pero existen pequeños matices que pueden llegar a establecer diferencias sustanciales a la hora de su interpretación. El artículo 51 del texto de 1976 detalla las condiciones de infraestructura y suministros que de modo gratuito deben ser garantizados por el Estado (seminternados, internados, becas y material escolar), de forma que con independencia de la condición económica de los familiares del educando, éste pueda acceder en plenitud a los estudios. Por su parte, el artículo 73 del texto de 2019 estipula sólo la garantía de la institución educativa, lo cual no implica necesariamente alojamiento y material escolar. De ser interpretado de manera literal el precepto constitucional, basta con que existan las edificaciones para clase y los maestros que impartan la docencia. Este camino interpretativo llevaría a una regresión en el derecho, lo cual vulnera el requisito de fundamentalidad de no regresión.

Otro aspecto que implica una regresión, es lo relativo a la posibilidad de la remuneración del postgrado o de estudios complementarios. El propio artículo 73 de la carta de 2019, en su último párrafo, reconoce y ampara legalmente este tipo de pago, aunque sea con carácter excepcional. Estaría amparándose así la práctica, hasta este momento inconstitucional, de los llamados repasadores pagados, que hacen competencia, en no pocas ocasiones, a las escuelas estatales; superándolas en la calidad de la docencia en asignaturas claves para garantizar la continuidad de estudios (matemática, español e historia), pero propiciando diferencia de oportunidades

16 Constitución de la República de Cuba, La Habana, Dirección de Legislación y Asesoría MINJUS, 2005, pp. 38 y 39.

17 Constitución de la República de Cuba, La Habana, Editora Política, 2019, p. 21. 
entre los educandos que pertenecen a una familia que puede pagar dichos cursos y una que no lo puede hacer. La Constitución de 1976, con sus reformas, no admitía la posibilidad de la remuneración, ni siquiera con carácter excepcional para el postgrado o para estudios complementarios.

Es algo suficientemente demostrado que la cobertura educativa de Cuba es total, y que ha sido política de Estado garantizarla en todos los niveles de enseñanza; sin embargo, esto no quiere decir que sea imposible que se susciten conflictos alrededor del servicio: en cuanto a la calidad, accesibilidad a determinados centros especializados, decisiones administrativas injustificadas y lesivas, o formas concretas de organización de la prestación que puedan hacer del servicio algo inaccesible para determinados sectores de la población.

Como parece advertir la Ley adjetiva de 1977, todos los conflictos referidos deben ser resueltos por medio de procedimientos internos, ministeriales o de órganos territoriales; o bien, por formas políticas alternativas de resolución, que en ocasiones generan decisiones con pocos visos de legalidad, e incluso arbitrarias; máxime si el propio Ministerio de Educación es a la vez el único prestador del servicio y el ente regulador de la actividad, lo que lo convierte de hecho en juez y parte.

Si se entiende que la prestación o servicio público en general se concreta mediante una relación jurídica de tipo prestacional y de naturaleza pública, por medio de la cual la administración contrae obligaciones con los beneficiarios a partir de un vínculo de derecho público, en este caso, como en toda relación jurídica bilateral, tanto el que presta el servicio como el beneficiario tienen derechos y obligaciones, y la realización de esos derechos y obligaciones puede suscitar controversias. Por ello es conveniente que se estipule una autoridad imparcial y una vía segura para dirimir dichas controversias, evitando que en la resolución del conflicto intervenga alguien en la doble condición de ejecutante y árbitro.

Pareciera que la nueva Constitución de la República de Cuba, de abril de 2019, está orientada a resolver esta presunta o potencial contradicción, estipulando en los artículos del 92 al 100 las garantías jurisdiccionales a los derechos. Sin embargo, la propia Constitución neutraliza la posibilidad de la eficacia autoaplicativa o directa: el artículo 99, en su párrafo final estipula: "La ley establece aquellos derechos amparados por esta garantía, y el procedimiento preferente, expedito y concentrado para su 
cumplimiento". ${ }^{18}$ Esta fórmula reenvía a las leyes especiales la determinación de los derechos que serán amparados, lo cual implica que algunos no lo serán necesariamente. Se rompe así con el principio de indivisibilidad de los derechos y con la eficacia directa de la Constitución, y habría que esperar a leyes especiales la determinación o no de la tutela judicial efectiva para el derecho a la educación.

Conferir tutela judicial efectiva a los reclamos de los administrados que son beneficiarios del servicio público de enseñanza o educativo, y sustraer la resolución de controversias de la propia administración pública, como única y última instancia, le da credibilidad y legitimidad a la propia administración, al tiempo que evidencia el compromiso del Estado para con sus ciudadanos.

Del análisis anterior se deduce que, si se sigue una posición concordante con la aludida doctrina italiana, y en parte predominante en Europa, sobre las características de la actividad prestacional de la administración, la educación en Cuba no puede encuadrarse, por lo menos desde el 6 de junio de 1961 y hasta el 2 de septiembre de 2013, como un típico servicio público. Carece de simultaneidad de prestadores públicos y privados, y de la referida tutela judicial efectiva. En este sentido encuadraría más como una función pública soberana del Estado, ejercida a través de su administración pública.

Se ha señalado como fecha conclusiva del periodo de exclusividad prestacional de la educación por la administración pública en Cuba el 2 de septiembre de 2013, porque este día fue promulgada la Resolución núm. 353 del Ministerio de Finanzas y Precios, por medio de la cual se aprobó como actividad privada o de "trabajo por cuenta propia" la de repasador, la cual se recoge en el anexo 1 de dicha resolución, en la tabla contentiva del régimen simplificado.

Debe destacarse que la acción de repasar es una forma específica de realización de la actividad educativa o de enseñanza, en la que no resulta fácil deslindar entre la reiteración de un viejo contenido y la introducción de uno nuevo. A ello se debe agregar que en materia de contenidos educativos se puede estar haciendo alusión al sistema de conocimientos, a las habilidades, a los valores, al desarrollo de capacidades y/o competencias. La pretensión del legislador de limitar sólo a la actividad de repaso esta inter-

18 Ibidem, p. 29. 
vención privada no es más que eso, una pretensión, que no se corresponde con los planteamientos teóricos y la práctica educativa contemporánea.

Esta disposición infraconstitucional, contradecía el espíritu del artículo 39 de la Constitución de 1976; pero se resuelve dicha contradicción con el artículo 73 de la nueva Constitución de 2019, eliminando uno de los elementos que podría vetar la consideración de la educación como prestación o servicio público: la de exclusividad de ejercicio por el Estado. Sin embargo, el de la prohibición legal de la tutela judicial efectiva se mantiene en la referida Ley de Procedimiento Civil, Administrativo y Laboral, la que no ha sido reformada, para pesar del ordenamiento jurídico cubano y de los destinatarios del servicio educativo.

Otro aspecto a considerar, luego de la aprobación de cierta actividad asociada a la enseñanza por privados, desde 2013, es el de las tarifas que se cobran por la misma. Al respecto Parada Vázquez plantea:

La remuneración del concesionario o gestor privado del servicio es también un precio privado, pero intervenido, debiendo incluirse en los contratos de gestión de servicios las tarifas máximas y mínimas que hubieran de percibirse de los usuarios, con descomposición de sus factores constitutivos, y procedimientos para su revisión... ${ }^{19}$

La regulación de las tarifas de actividades consideradas servicios públicos, es otra ausencia en la Resolución núm. 353 del Ministerio de Finanzas y Precios. Mediante el uso del derecho comparado se aprecia que la tendencia en países con cierta tradición tributaria, como Alemania, Francia y España, es que la administración pública intervenga en las tarifas de actividades realizadas por los privados, si están consideradas un servicio público por el ordenamiento jurídico; esto independientemente del título habilitante que les permita el ejercicio de la prestación.

La situación descrita ubica a la actividad educativa como prestación pública en un estado de indefensión ante arbitrariedades de la administración; e incluso en situaciones de desventaja para los beneficiarios, ante la actuación del emergente sector "privado" de repasadores, que viene abriéndose paso, cabalgando sobre el lomo de la Resolución núm. 353. Esta situación se agrava en un ordenamiento jurídico poco garantista, donde las decisio-

19 Parada Vázquez, Ramón, Derecho administrativo I, parte general, Madrid, Marcial Pons, Ediciones Jurídicas, 1991, p. 432. 
nes de la administración pública en materia educativa, hasta el momento, no pueden ser revisadas en proceso judicial, por más vulneradora que sea del derecho de los beneficiarios.

La realidad expuesta es independiente de la gran voluntad política que pueda tener uno u otro funcionario; pues de lo que se trata es de las garantías y de la seguridad jurídica que ofrece el ordenamiento, y no de los niveles de concreción material en cuanto a amplitud de cobertura educativa. Ello supone identificar las principales limitaciones jurídico-formales que tiene la educación en Cuba para ser entendida como un servicio público, lo que la ubica preferentemente en la categoría de función pública soberana del Estado.

\section{LA EDUCACIÓN EN CUBA: PRINCIPALES LIMITACIONES A LA LUZ DE LA TEORÍA DE LOS DERECHOS FUNDAMENTALES}

Existe una evidente conexión entre los llamados derechos fundamentales de prestación y la actividad administrativa de prestación o servicio público: los primeros se refieren a quién tiene la facultad de exigir de la administración pública una conducta debida de prestación o satisfacción de una necesidad básica, es decir: quién es el sujeto activo y qué facultades le asisten en una relación iusfundamental; lo segundo se refiere a quién tiene la obligación iusfundamental de garantizar el derecho, y a través de qué tipo de actividad de la administración pública se satisface ese derecho. Esto supone tener en cuenta cómo se garantiza su materialización.

La complejidad para designar al repertorio de derechos fundamentales es tal, que incluso, en el derecho constitucional y en los tratados internacionales, aparecen otras designaciones como derechos humanos, derechos constitucionales, libertades individuales y derechos del hombre.

El constitucionalista español Pérez Tremps atribuye esta diversidad de designaciones en el derecho constitucional a varios motivos, que van desde la perspectiva metodológica con que se analiza una misma realidad jurídica, pasando por la dimensión histórica, hasta llegar a la estructura interna de los distintos derechos. ${ }^{20}$

A pesar de esta diversidad de designaciones, el autor coincide con Pérez Tremps cuando plantea que

${ }^{20}$ López Guerra, Luis et al., Derecho constitucional, El ordenamiento constitucional, derechos y deberes de los ciudadanos, vol. I, Valencia, Tirant lo Blanch, 2000. 
...desde el puno de vista constitucional, el concepto de "derechos fundamentales" resulta el más adecuado; ello porque, por otra parte, la expresión "derechos fundamentales" sirve para poner de manifiesto la naturaleza especial que dichos derechos poseen: su consideración como elemento básico y preeminente del ordenamiento, frente a la naturaleza "ordinaria" que los demás derechos subjetivos poseen. ${ }^{21}$

También se debe considerar que la doctrina y la legislación constitucional emplean el término derechos fundamentales en dos sentidos: uno amplio, y considerado técnicamente incorrecto por algunos autores, ${ }^{22}$ que le atribuye tal calificativo a cualquier derecho plasmado en la Constitución; y uno estricto, reservado para aquellos derechos que conforman el núcleo central del estatus jurídico del individuo. Estos derechos son los que en Constituciones como la española manifiestan una especial rigidez exigida para su reforma, y gozan de un reforzado sistema de garantías normativas en las leyes de desarrollo.

Autores como el español Pérez Luño definen los derechos fundamentales como "el conjunto de facultades, instituciones y prerrogativas que en cada momento histórico concretan la exigencia de la dignidad, la libertad y la igualdad humanas, las cuales deben ser reconocidas positivamente por los ordenamientos jurídicos...". 23

Para Villabella Armengol los derechos fundamentales son aquellos dentro de los mismos derechos constitucionales y humanos, que además de positivarse han logrado que se les instrumenten vías garantistas seguras para su defensa e implementación. ${ }^{24}$

Por su parte, Javier Pérez Royo expresa:

Los derechos fundamentales son, pues, los derechos naturales constitucionalizados sobre la base del principio de soberanía popular. No basta, por tanto, que los derechos sean enumerados sin más en la Constitución... Para que los

21 Ibidem, p. 138.

22 Pablo Pérez Tremps, Luis López Guerra, Eduardo Espín, Juaquín García Morillo, Miguel Satrústegui, etcétera.

23 Pérez Luño, Antonio Enrique, Los derechos fundamentales, Madrid, Tecnos, 1994, p. 44.

24 Villabella Armengol, Carlos Manuel, "Los derechos humanos. Consideraciones teóricas de su legitimación en la Constitución cubana”, en Prieto Valdés, Martha (comp.), Selección de textos constitucionales, primera parte, La Habana, ENPSES, 1991, p. 91. 
derechos se conviertan en derechos fundamentales tienen que incorporarse a una Constitución que se afirme expresamente como norma jurídica y que prevea mecanismos para garantizar su supremacía sobre todas las demás normas del ordenamiento y en particular sobre la ley. Los derechos fundamentales están, por tanto, en íntima conexión con las garantías constitucionales... ${ }^{25}$

\section{Para Luigi Ferrajoli son derechos fundamentales:}

...todos aquellos derechos subjetivos que corresponden universalmente a "todos" los seres humanos en cuanto dotados del status de personas, de ciudadanos o personas con capacidad de obrar; entendiendo por "derecho subjetivo" cualquier expectativa positiva (de prestaciones) o negativa (de no sufrir lesiones) adscrita a un sujeto por una norma jurídica; y por "status" la condición de un sujeto, prevista asimismo por una norma jurídica positiva, como presupuesto de su idoneidad para ser titular de situaciones jurídicas y/o autor de los actos que son ejercicio de éstas. ${ }^{26}$

Obsérvese que en las dos últimas definiciones parece existir una doble influencia de iusnaturalismo y positivismo jurídico, con diferencia de énfasis, pero sin pretender anclar los conceptos a las tradicionales posiciones metafísicas de los autores precursores. Lo que interesa, a los efectos de este trabajo, es que tanto Pérez Royo como Ferrajoli coinciden en la importancia de instrumentar garantías a los derechos, y éstas suponen básicamente la positivación de acciones de protección o defensa, así como la previsión de mecanismos para exigir prestaciones del Estado.

La definición del maestro italiano, por demás, reconoce que dentro de los derechos fundamentales se pueden concebir las expectativas positivas o prestacionales, lo que haría de los derechos económicos, sociales y culturales facultades susceptibles de fundamentalidad, y por ello de garantías frente al Estado y terceros. El supuesto implicaría el derecho a accionar por el mero incumplimiento de la prestación debida, o incluso la exigibilidad de garantizar una prestación de calidad. Dentro de este supuesto, entrarían a formar parte derechos como la educación, la salud o la seguridad social.

25 Pérez Royo, Javier, Curso de derecho constitucional, Madrid, Marcial Pons, Ediciones Jurídicas y Sociales, 1997, p. 256.

${ }^{26}$ Ferrajoli, Luigi, Derechos y garantías, La ley del más débil, Madrid, Editorial Trotta, 2004, p. 37. 
Por su parte, Pérez Royo plantea cuáles son las garantías constitucionales que elevan a rango de derechos fundamentales los derechos plasmados en una Constitución. Para ello toma de referencia la experiencia española. En una taxonomía, a juicio de este autor interesante, las divide en garantías objetivas o institucionales, garantías subjetivas o individuales y garantías orgánicas. ${ }^{27}$

Dentro de las garantías objetivas o institucionales se señalan, por el referido autor, las garantías constitucionales propiamente dichas. Entre estas enumera la rigidez para la reforma constitucional y el control de constitucionalidad de la ley. A las anteriores adiciona el principio de legalidad o de reserva de ley y sus garantías complementarias, y las garantías frente a la distribución territorial del poder.

Por su parte, dentro de las garantías subjetivas o individuales enumera la tutela judicial efectiva de los derechos fundamentales en la jurisdicción ordinaria, la garantía judicial preferente y sumaria de estos derechos, y la garantía de amparo constitucional. Estas garantías se pueden encuadrar dentro de una más genérica consistente en la judicialización de los derechos fundamentales.

Como garantía orgánica menciona la existencia del Defensor del Pueblo, dependiente en España del Poder Legislativo y capaz de ejercer las acciones de inconstitucionalidad y amparo ante el Tribunal Constitucional. Es un órgano en el que no se pretende profundizar, pero a pesar de las objeciones que pueda suscitar, sobre todo por lo limitado de sus competencias, constituye otra forma de garantizar los derechos de los ciudadanos ante violaciones por parte de la administración pública.

Otra significativa clasificación taxonómica de garantías a los derechos fundamentales es la propuesta por el maestro italiano Luigi Ferrajoli, quien las divide en primarias y secundarias. Dentro de las primeras, ubica a las obligaciones de prestación y a las prohibiciones de lesión, concebidas como expectativas positivas o negativas frente al Estado o terceros; mientras que dentro de las garantías secundarias prevé las obligaciones de reparar y sancionar judicialmente los derechos, “...es decir, las violaciones de sus garantías primarias". ${ }^{28}$

27 Pérez Royo, Javier, Curso de derecho constitucional, Madrid, Marcial Pons, Ediciones Jurídicas y Sociales, 1997, p. 256.

28 Ferrajoli, Luigi, Derechos y garantías..., cit., p. 37. 
Es interesante apreciar que ambos autores coinciden en ubicar dentro de las garantías a los derechos fundamentales la tutela judicial efectiva, el primero bajo la denominación de garantías subjetivas o individuales, a la vez que el segundo las denomina garantías secundarias. Ambas posiciones, con diferentes matices clasificatorios, muestran una tendencia creciente que se percibe como requisito para caracterizar el llamado Estado constitucional de derechos: ${ }^{29}$ la judicialización de la protección de los derechos fundamentales como principal garantía ante el incumplimiento o las lesiones provocadas por el Estado o terceros.

Al respecto, autores como Pahuamba Rosas y Zavala Gallardo señalan:

El derecho tiene que existir en el sistema normativo y la falta de cumplimiento genera la posibilidad de su reclamo en instancias judiciales. Asimismo, se requiere una ley donde se establezca la forma en la que se desarrolla el derecho, su alcance y la forma de exigirlo. No obstante ello, el operador judicial puede entrar al estudio y determinar el incumplimiento, así como la sanción al obligado, tratándose de derechos de orden constitucional en el caso de que no exista ley que lo reglamente. Según una afirmación ampliamente difundida en el discurso jurídico, el carácter normativo de las Constituciones contemporáneas residiría en la existencia de un control jurisdiccional de las mismas, capaz de imponer su contenido, llegado el caso, a los propios poderes encargados de desarrollarla. ${ }^{30}$

Puede concluirse que, para los autores abordados, los derechos fundamentales son aquellos derechos constitucionales que gozan de un plus de fundamentalidad, es decir, tienen dentro del ordenamiento jurídico eficacia directa, reserva de ley o indisponibilidad legislativa para la regresión, contenido esencial o mínimo reconocido, y un sistema amplio de garantías jurisdiccionales, entre las cuales la tutela judicial efectiva es la de más amplia aceptación doctrinal y la más difundida en el derecho positivo. ${ }^{31}$

Esta postura, aunque desde el punto de vista jurídico-formal es un paso de avance, por su enfoque garantista, contiene algunas limitaciones pro-

29 Definición asumida por Luigi Ferrajoli en Derechos y garantías. La ley del más débil, para significar la superación del tradicional Estado liberal de derechos, así como la presunta crisis del Estado social de derechos.

${ }^{30}$ Pahuamba Rosas, Baltazar y Zavala Gallardo, Erick (coords.), Aplicación de los derechos humanos, México, Editorial Liber Iuris Novum, 2014, pp. 187 y 188.

31 Pérez Royo, Javier, Curso de derecho constitucional, cit., pp. 345-350. 
pias del enfoque positivista del derecho, al negar la fundamentalidad de nuevos derechos que pudieran aparecer y que aún no están consagrados en normas de derecho escrito. Preferimos asumir que los derechos fundamentales son todos aquellos derechos inherentes al hombre, por consagrar los valores supremos de libertad, dignidad, solidaridad e igualdad humanas; y que entonces por ello, y sólo por ello, deben ser positivados para su mejor protección, especialmente en lo relativo a las garantías.

Otro asunto, especialmente complejo, es si los llamados derechos prestacionales o de prestación pueden considerarse derechos fundamentales, y si gozan del mismo plus de fundamentalidad que los llamados derechos de libertad o derechos civiles y políticos. La concepción del liberalismo social desecha por completo esta postura, y en Constituciones como la española de 1978, inspirada en el llamado modelo del Estado social y democrático de derechos, se estipulan como principios económicos y sociales del Estado. Esto supone un rango de protección iusfundamental menor, y por ello "garantías" menos plenas.

El propio Ferrajoli reconoce la existencia de carencias teóricas y legislativas en cuanto al reconocimiento de fundamentalidad a los derechos de prestación cuando expresa:

Es indudable que la ciencia del derecho no ha elaborado aún - frente a las violaciones que derivan de la omisión de prestaciones - formas de garantía comparables en eficacia y sencillez a las previstas para los demás derechos fundamentales, tanto de libertad como de autonomía. A diferencia de estos últimos derechos, que asumen la forma de expectativas negativas frente a las que corresponde el deber de los poderes públicos de no hacer (o prohibiciones), los derechos sociales imponen deberes de hacer (u obligaciones). Su violación no se manifiesta, por tanto, como en el caso de los de libertad, en la falta de validez de actos - legislativos, administrativos, o judiciales - que pueden ser anulados por vía jurisdiccional, sino en lagunas de disposiciones y/o carencias en las prestaciones que reclamarían medidas coercitivas no siempre accionables. ${ }^{32}$

Esta postura, sin embargo, da continuidad a una tradicional división liberal entre derechos de libertad y derechos de prestación, considerando los primeros como esfera de abstención de intervención del Estado, exigibles judicialmente; mientras que los segundos son declaraciones políticas

32 Ferrajoli, Luigi, Derechos y garantías..., cit., p. 109.

Esta obra está bajo una Licencia Creative Commons

Atribución-NoComercial-SinDerivar 4.0 Internacional, IIJ-UNAM. 
realizables según las posibilidades económicas de cada país, y nunca exigibles judicialmente. Para autores como Van Hoof esta división es ficticia, y en su lugar proponen cuatro niveles de obligaciones estatales en el plexo de derechos fundamentales: una obligación de respetar, una obligación de proteger, una obligación de garantizar y una obligación de promover el derecho en cuestión. ${ }^{33}$

Como plantean Abramovich y Curtis:

Ninguno de estos niveles puede caracterizarse únicamente a través de las distinciones obligaciones negativas/obligaciones positivas, $u$ obligaciones de resultado/obligaciones de medio, aunque ciertamente las obligaciones de proteger, asegurar y promover parecen envolver un mayor activismo estatal $\mathrm{y}$, por ende, un número mayor de obligaciones positivas o de conducta. ${ }^{34}$

La idea planteada por los autores se centra en la unidad entre los llamados derechos civiles y políticos (o derechos de libertad) y los derechos económicos, sociales y culturales (o derechos de prestación).

El autor de esta investigación asume la posición que relativiza la clásica división entre derechos de libertad y derechos de prestación (o económicos, sociales y culturales), pues considera que todos los derechos están relacionados entre sí, y todos requieren de una intervención del Estado, aunque con grados diferentes de intensidad. En unos debe realizar una prestación directa para que se garantice el derecho, en otros debe crear condiciones para que los derechos se puedan realizar sin trabas, o incluso intervenir con sus órganos cuando hay vulneraciones ilegítimas.

Negarles a los derechos de prestación la condición de derechos fundamentales tiene consecuencias jurídicas, que se expresan de manera clara en muchos ordenamientos jurídicos europeos y latinoamericanos. Su principal consecuencia es negarle la tutela judicial efectiva, tanto en procesos constitucionales especiales como en procesos judiciales ordinarios.

Por su parte, en el campo del derecho internacional de los derechos humanos también se ha suscitado el debate. Particularmente, en el caso

33 Van Hoof, G. H. J, "The legal Nature of Economic, Social and Cultural Rights. A Rebutall of SomeTraditional Views", en Alston, P. y Tomasevski, K. (eds.), The Right to Food, Martinus Nijhoff, Utrecht, 1984, pp. 97-110.

34 Abramovich, V. y Curtis, C., Los derechos sociales como derechos exigibles, 2a. ed., Madrid, Trotta, 2004, p. 123. 
de la educación, la Declaración Universal de los Derechos Humanos, en su artículo 26 la define como un derecho humano desde 1948. Al respecto esta norma de derecho internacional estipula:

1. Toda persona tiene derecho a la educación. La educación debe ser gratuita, al menos en lo concerniente a la instrucción elemental y fundamental. La instrucción elemental será obligatoria. La instrucción técnica y profesional habrá de ser generalizada; el acceso a los estudios superiores será igual para todos, en función de los méritos respectivos.

2. La educación tendrá por objeto el pleno desarrollo de la personalidad humana y el fortalecimiento del respeto a los derechos del hombre y a las libertades fundamentales; favorecerá la comprensión, la tolerancia y la amistad entre todas las naciones y todos los grupos étnicos y religiosos; promoverá el desarrollo de la actividad de las Naciones Unidas para el mantenimiento de la paz.

3. Los padres tendrán derecho preferente a escoger el tipo de educación que habrá de darse a sus hijos. ${ }^{35}$

En igual sentido se pronuncia el artículo 13 del Pacto Internacional de Derechos Económicos, Sociales y Culturales, aprobado el 16 de diciembre de 1966, y en vigor desde el 3 de enero de 1976. A pesar de estos tratados internacionales, las legislaciones internas de los Estados, la jurisprudencia y la doctrina han rechazado la justiciabilidad de los derechos económicos, sociales y culturales.

Sin embargo, en el sistema interamericano se aprecian avances por vía de interpretación progresiva de la Corte Interamericana de Derechos $\mathrm{Hu}$ manos. Al respecto, este órgano jurisdiccional supranacional se pronunció en el caso Niñas Yean y Bosico vs. República Dominicana respecto al papel del Estado dominicano en garantizar el derecho a la educación:

...de acuerdo al deber de protección especial de los niños consagrado en el artículo 19 de la Convención Americana, interpretado a la luz de la Convención para los Derechos del Niño y del Protocolo adicional de la Convención Americana sobre Derechos Humanos en materia de Derechos Económicos, Sociales y Culturales, en relación con el deber de desarrollo progresivo en el

35 Declaración Universal de los Derechos Humanos, aprobada y proclamada por la Asamblea General de las Naciones Unidas mediante resolución 217 A (III), del 10 de diciembre de 1948. 
artículo 26 de la Convención Americana, el Estado debe proveer educación primaria gratuita a todos los menores, en un ambiente y condiciones propicias para su pleno desarrollo intelectual. ${ }^{36}$

Si bien, en un inicio, la justiciabilidad de los derechos sociales se sustentaba con base en el principio de interdependencia de éstos con los civiles y políticos, dicha solución técnica ofreció un marco interpretativo que permitía extender la protección de los derechos humanos al campo de los económicos, sociales y culturales. La propia Corte Interamericana ha basado sus fallos al respecto en la jurisprudencia del Tribunal Europeo de Derechos Humanos, el que en fecha tan temprana como 1979 había establecido:

...si bien el Convenio recoge derechos esencialmente civiles y políticos, gran parte de ellos tienen implicaciones de naturaleza económica y social. Por eso el Tribunal estima, como lo hace la Comisión, que el hecho de que una interpretación del Convenio pueda extenderse a la esfera de los derechos sociales y económicos no es factor decisivo en contra de dicha interpretación, ya que no existe una separación tajante entre esfera y campo cubierto por el Convenio. ${ }^{37}$

Incluso esta postura, que en su época fue de avanzada, ha sido superada por una visión enfocada en la justiciabilidad autónoma de los derechos económicos, sociales y culturales.

Por su parte Robert Alexy, luego de abordar los derechos de defensa del ciudadano frente al Estado, plantea:

Su contrapartida son los derechos a acciones positivas del Estado, que deben ser incluidas en el estatus positivo en sentido estricto. Si se presupone un concepto amplio de prestación, todos los derechos a acciones positivas del Estado pueden ser calificados como derechos a prestaciones del Estado en un sentido amplio; dicho brevemente: como derechos a prestaciones en sentido amplio. ${ }^{38}$

36 Caso Niñas Yean y Bosico vs. República Dominicana. Sentencia de la CIDH del 8 de septiembre de 2005, serie C, núm. 130, párr. 185.

37 Caso Airey vs. Irlanda No. 6289/73. Sentencia del TEDH del 9 de octubre de 1979, párr. 26.

38 Alexy, Robert, Teoría de los derechos fundamentales, Madrid, Centro de Estudios Constitucionales, 1993, p. 419. 
Es indudable que a pesar de su concepción amplia sobre los derechos de prestación, no sólo no los excluye de considerarlos derechos fundamentales, sino que cree son partes constitutivas de éstos. Para esclarecer su posición plantea:

En tanto derechos subjetivos, todos los derechos a prestaciones son relaciones trivalentes entre un titular de derecho fundamental, el Estado y una acción positiva del Estado. Si un titular de un derecho fundamental (a) tiene un derecho frente al Estado (e) a que éste realice la acción positiva $(h)$, entonces, el Estado tiene frente a $(a)$ el deber de realizar $(h)$. Cada vez que existe una relación de derecho constitucional de este tipo entre un titular de un derecho fundamental y el Estado, el titular de derecho fundamental tiene competencia para imponer judicialmente el derecho. ${ }^{39}$

Es de destacar que la forma que Alexy encuentra para resaltar el carácter de derecho fundamental a los derechos de prestación es la de otorgarles tutela judicial efectiva ante la posible vulneración del derecho. Esta estrategia argumentativa del autor evidencia el consenso que existe en la comunidad científica sobre la necesidad de conferirles a los titulares de los derechos fundamentales una vía judicial de defensa.

Pero la vía judicial de defensa no cumple la mera función de inhibir al Estado o, en su caso, a la administración pública, de una intervención ilegítima en un derecho de un ciudadano; sino que es una compulsión positiva, con respaldo coactivo, para actuar. Es la única forma que el ciudadano, o en su caso el administrado, tiene para evitar que el derecho fundamental sea una mera declaración política que adorna la Constitución, o que sólo dependa de la "buena" voluntad de determinados políticos, y no de su deber de ejercer la función pública que le ha sido conferida por mandato constitucional o legal.

Autores como Luigi Ferrajoli, analizando el contexto en el que realizan sus reflexiones, vinculan la fundamentalización de los derechos económicos, sociales y culturales a la formalización y universalización de los mismos, como “...técnicas de garantía más idóneas para asegurar el máximo de igualdad, de transparencia, de automaticidad y por consiguiente de eficacia". ${ }^{40}$

39 Ibidem, p. 431.

${ }^{40}$ Ferrajoli, Luigi, Derechos y garantías, La ley del más débil, Madrid, Trotta, 2004, p. 112.

Esta obra está bajo una Licencia Creative Commons

Atribución-NoComercial-SinDerivar 4.0 Internacional, IIJ-UNAM. 
No se niega la importancia de estas garantías propuestas por el profesor italiano, pero consideramos que por sí solas son insuficientes, pues los ejemplos de lo ocurrido con los modelos del Estado social de derecho y del socialismos real así lo demuestran. En dichos modelos, tales garantías se han utilizado primero para la manipulación política y la dominación ideológica, y luego se han abolido de un plumazo por gobiernos que han aplicado terapias de choque con fines de racionalización económica. Nos parece más apropiado combinar estas garantías con otras propuestas por el propio Ferrajoli, dentro de las que incluye “...una formalización de los procedimientos de garantía de los derechos sociales aún más eficaz y garantista que la prevista para los derechos de libertad". ${ }^{41}$

Los funcionarios públicos no perduran por siempre, por muy asidos que estén al cargo; su voluntad política o discrecionalidad no pueden ser la fuente generadora de seguridad jurídica para los derechos económicos, sociales y culturales. Garantizar por tutela judicial efectiva los derechos fundamentales de prestación hace de éstos una realidad perdurable y exigible, y no una divisa de legitimación personal para el ejercicio del poder.

Si los Estados liberales y sus ideólogos han rechazado el carácter de fundamentales a los derechos de prestación, el autor considera que en los Estados de "bienestar" y en los modelos socialistas, debe ocurrir lo contrario, sustentado en el enfoque social de sus ordenamientos jurídicos. Este planteamiento tiene dos fundamentos: cuando los funcionarios públicos de un Estado se ven obligados a seguir una conducta por disposición normativa de rango constitucional, están compulsados a observar dicha conducta, pues saben que lo contrario trae consecuencias legales para ellos; y las decisiones en materia de políticas públicas que éstos toman no pueden ser vistas como un favor a la comunidad, sino como el cumplimiento de un mandato constitucional.

Por lo anterior, ordenamientos jurídicos desarrollados, en que se postula la adscripción al modelo de Estado constitucional de derechos, la falta de diligencia del órgano Legislativo para aprobar leyes de desarrollo de los derechos fundamentales, o del Ejecutivo para promulgarlas, configuran los requisitos de una acción de inconstitucionalidad por omisión legislativa.

Las ideas abordadas hasta aquí permiten articular la concepción de la educación como prestación o servicio público con la configuración del

41 Ibidem, p. 112 . 
derecho fundamental a prestación educativa del Estado en favor del ciudadano. En el plano estrictamente administrativo sería un derecho a un servicio público del administrado frente a la administración; pero a la vez un derecho fundamental del ciudadano y, más aún, de cualquier ser humano, ${ }^{42}$ frente al Estado.

Para restarle importancia a que el derecho a la educación en Cuba no goza de tutela judicial efectiva, se pudiera argumentar que este derecho es materialmente garantizado por el Estado, al menos en lo relativo a la masividad de su acceso. Sin embargo, contra este planteamiento puede esgrimirse la posición de Robert Alexy cuando expresa:

Quien desee trazar un cuadro completo de los derechos fundamentales no puede excluirlo tan sólo porque esté satisfecho. Como, a menudo, la satisfacción de un derecho fundamental cuesta algo de no satisfacción de otro derecho fundamental, el derecho fundamental satisfecho sigue siendo importante como razón jurídico-constitucional para la justificación de tales no satisfacciones. Pero, sobre todo, vale el hecho de que de la satisfacción de un derecho en el pasado y en el presente no puede inferirse su satisfacción en el futuro. Si no existiera ningún derecho fundamental, el legislador tendría una porción de libertad y competencia que no tendría si existiera. Como nadie conoce al futuro legislador y las circunstancias bajo las cuales habrá de actuar, nadie puede estar seguro de que - a diferencia de lo sucedido en el pasado y de lo que sucede en el presente- no hará de aquellas libertades y competencias, un uso desfavorable para el individuo. ${ }^{43}$

Aquí, es trascendente la seguridad jurídica en el marco de la protección iusfundamental. Se trata de que no es suficiente una actuación fáctica del Estado, aunque ésta incluso logre satisfacer las necesidades sociales a plenitud. La administración pública puede trazar determinadas políticas dirigidas a realizar prestaciones orientadas a demandas, pero una política pública no tiene que llegar a estar respaldada en un derecho fundamental, por lo que no es exigible al Estado, y particularmente a la administración pública.

42 Principalmente si se asume la taxonomía clasificatoria de Luigi Ferrajoli sobre los derechos fundamentales, comprendiendo dentro de éstos a los humanos, que son inherentes a cualquier hombre, independientemente de su estatus de ciudadanía. Este autor ubica el derecho a la educación dentro de este tipo de derechos en su obra Derechos y garantías. La ley del más débil, publicado por Trotta en 2004.

43 Alexy, Robert, Teoría de los derechos fundamentales, Madrid, Centro de Estudios Constitucionales, 1993, p. 434. 
También puede ocurrir que los funcionarios o agentes de la administración cometan arbitrariedades, incluso estando reconocido el derecho, y se prive a los beneficiarios de su disfrute, o se lesione de alguna manera dicho disfrute (prestaciones sin calidad, o incompletas, entre otras); para estos casos se hace necesario proveer medios de protección frente a tales arbitrariedades.

Coincidiendo con lo anterior, y analizando en particular el caso de protección de los derechos fundamentales en Cuba, los profesores Ángel Meriño, Danelia Cutié y Josefina Méndez plantean:

Por ello no es admisible afirmar que una sociedad, al crear un conjunto de condiciones políticas y materiales, garantiza por sí misma la tutela y protección de los citados derechos, pues aun las sociedades más justas y democráticas no están exentas de violaciones a los derechos, toda vez que las palancas del ejercicio del poder y del gobierno están en manos de hombres que no son libres de cometer excesos. Lo anterior nos lleva a afirmar que además de crear las condiciones materiales para el ejercicio del derecho del hombre, el Estado ha de establecer las vías para ampararlos. ${ }^{44}$

Como se ha reiterado, parece que la tutela judicial efectiva de los derechos fundamentales, particularmente del derecho a prestaciones educativas, es una de las garantías más eficaces ante posibles vulneraciones o desamparos de la administración. Su articulación coherente en el ordenamiento jurídico posibilita que el derecho se materialice en prestaciones o servicios públicos educativos, con la seguridad jurídica requerida para ello.

Esta configuración protege a los ciudadanos titulares del servicio educativo de dos posibles situaciones vulneradoras: un cambio repentino de las políticas pública por los funcionarios administrativos o el Legislativo, dirigido a suprimir o reducir el alcance de dichas políticas; y hechos aislados de incumplimiento del derecho fundamental a prestaciones educativas por funcionarios encargados de poner en práctica las políticas. Sólo la constitucionalización del derecho, y sus garantías jurídicas pueden favorecer canales seguros y eficaces de protección para los beneficiarios del servicio.

44 Mariño, Ángel et al., "Reflexiones en torno a la protección de los derechos fundamentales en Cuba. Propuesta para su perfeccionamiento. Otro derecho", en Prieto Valdés, Martha y Pérez Hernández, Lissette (comps.), Selección de textos constitucionales, primera parte, La Habana, ENPSES, 1994, p. 94. 
El ejemplo analizado arriba, sobre los cambios de la Constitución cubana de 2019 con relación a la Constitución reformada de 1976, en materia educativa, es una pequeña muestra de lo que podría ocurrir sin las garantías contenidas en los requisitos de fundamentalidad. El simple hecho de que no se describan de forma detallada las garantías materiales, como se hacía en el texto anterior, y que se posibilite, aunque con carácter excepcional, el cobro por determinados servicios educativos podría ser interpretado por la doctrina garantista como una regresión, lo que es incompatible con la teoría de los derechos fundamentales.

\section{LA EDUCACIÓN EN CUBA Y EL CUMPLIMIENTO DE LOS REQUISITOS DE FUNDAMENTALIDAD}

Como se ha referido, a pesar de la amplia cobertura que presenta en Cuba la educación, y las altas cuotas de financiamiento que destina el Estado a este "servicio público", el ordenamiento jurídico cubano no parece concebir la educación como un derecho fundamental; por lo menos en cuanto al cumplimiento de los requisitos de fundamentalidad para dichos derechos, ampliamente aceptados en la doctrina y en el derecho comparado.

Al respecto se analizará el grado de cumplimiento de algunos de los requisitos de fundamentalidad para el derecho a la educación en Cuba, al menos en su configuración jurídico-formal, como supuesto "servicio público", así como las principales limitaciones que éste presenta con base en su configuración real como función pública soberana del Estado.

\section{Eficacia directa y vinculación de todos} los "poderes" públicos

Este requisito de fundamentalidad, como expresa Pérez Royo:

...significa que los derechos fundamentales tienen una eficacia directa a partir de la propia Constitución y que no es necesaria, en consecuencia, una intervención del legislador para que los ciudadanos puedan ejercerlos, aunque tal intervención puede ser muy conveniente, dependiendo del derecho de que se trate. Pero el derecho ya está reconocido en la Constitución y ni 
su presencia en el ordenamiento ni su ejercicio por los ciudadanos depende de que el legislador actúe o deje de actuar. ${ }^{45}$

El capítulo VII de la Constitución de la República de Cuba de 1976 (reformada), titulado "Derechos, deberes y garantías fundamentales", en su artículo 51 plantea: "Todos tienen derecho a la educación..."; 46 seguidamente enumera el amplio sistema de garantías materiales en que se sustenta este mandato constitucional. Es evidente que la ubicación de este enunciado normativo en el referido capítulo haría pensar automáticamente que el derecho a la educación es un derecho fundamental en Cuba, y por tanto goza de eficacia directa.

Es cierto que la concepción de eficacia directa de la Constitución supone que para la aplicación de sus preceptos no se necesite ley de desarrollo, y por tanto una intervención del Legislativo en el sentido de legislar; pero para que esa eficacia sea real, en el sentido de atribuir efectos jurídicos, es necesario que algún órgano del Estado garantice dicha eficacia, vinculando a todos a través de una decisión de carácter imperativo.

Usualmente, en los ordenamientos jurídicos foráneos, la referida eficacia es garantizada por los tribunales ordinarios (sistema difuso), por un tribunal constitucional (sistema concentrado), o por la mezcla de ambos sistemas. Pero en el caso de Cuba no existe, desde 1973, ese órgano aplicador directo del precepto constitucional, con carácter vinculante y efectos generales, o no aparece dispuesto explícitamente en una norma de rango constitucional.

La única excepción, en el sentido antes señalado, es la relativa a las funciones garantes de la legalidad, atribuidas a la Fiscalía General de la República en el 127 constitucional, pero cuestionable en cuanto al efecto no vinculante de sus decisiones, y al doble papel de este órgano como representante del propio Estado en los procesos penales, y defensor de la aplicación estricta de la Constitución y las leyes. A lo anterior debe añadirse, como agravante, que no existe previsto un proceso expedito de amparo de los derechos fundamentales en Cuba, ante vulneraciones por parte del Estado o de terceros, a excepción del habeas corpus en materia penal y del amparo en la posesión en materia civil, con sus respectivas limitaciones.

45 Pérez Royo, Javier, Curso de derecho constitucional, Madrid, Marcial Pons, 1997, p. 345 .

46 Constitución de la República de Cuba, cit., pp. 38 y 39. 
Esta aparente laguna constitucional en materia de aplicación directa de la Constitución ha provocado cierta "auto-inhibición" por parte de los tribunales cubanos, la que se fundamenta en varias causales de orden histórico y político-jurídico que son señaladas por la profesora Martha Prieto Valdés. La misma esboza entre dichas causales “...el diseño funcional del aparato de poder estatal...", ${ }^{47}$ el que incluye la concentración de atribuciones legislativas, constituyentes y de revisión de constitucionalidad en manos de la Asamblea Nacional del Poder Popular; las atribuciones conferidas al Consejo de Estado, sin obligatoriedad de revisión de sus actos legislativos por parte de la Asamblea; la sustracción de las atribuciones para sentar jurisprudencia por parte del Tribunal Supremo Popular y, en general, la concepción de la unidad de poderes, que hace prácticamente inatacables las decisiones de los órganos supremos de poder del Estado, máxime cuando existe coincidencia en la composición directiva de los mismos.

En un sentido esperanzador, la referida autora señala:

Tampoco se ha formulado impedimento, ni se puede, de interpretar las disposiciones legales y generales conforme a la Constitución, o desde la Constitución, sino que ella puede y debe emplearse como norma patrón, de contraste en caso de lagunas, antinomias o desregulaciones conscientes, a los efectos de encontrar la solución al caso. No puede haber limitante para emplearla como marco jurídico para el control del funcionamiento del aparato estatal y la labor de los representantes populares; o para el aseguramiento de los derechos humanos fundamentales, como se hizo en su momento, recién promulgada la Constitución de $1976 .^{48}$

Lamentablemente, en el caso particular del derecho fundamental a la educación, sí existe en el ordenamiento jurídico cubano un impedimento para interpretar las disposiciones legales y generales conforme a la Constitución, o desde la Constitución. El referido artículo 657 de la Ley núm. 7, de Procedimiento Civil, Administrativo y Laboral de 1977, prohíbe expresamente someter a la jurisdicción administrativa los conflictos que se susciten en materia de actividad educacional.

47 Prieto Valdés, Martha, "En pos de la aplicabilidad directa de la Constitución cubana de 1976 (un breve comentario)", IUS Revista del Instituto de Ciencias Jurídicas de Puebla A.C. (21), 2008, p. 198.

48 Ibidem, p. 200. 
En el caso particular de la recientemente aprobada Constitución de 2019, el artículo 99, segundo párrafo, deja en manos del legislador ordinario la determinación de aquellos derechos que serán amparados por las garantías jurisdiccionales que la nueva carta magna estipula. Si prima el criterio del legislador de 1977, se sabe que prevalecerá el criterio de la educación como función pública soberana del Estado, en detrimento de su concepción como derecho fundamental. De lo contrario se abrirá el camino a la fundamentalidad del derecho. En cualquier caso, este autor considera la declaración final del referido artículo 99 una estocada a la eficacia directa de la Constitución, y por ello al principio o criterio autoaplicativo. Además, establece una división de los derechos que rompe los principios de interdependencia e indivisibilidad, hasta ahora defendidos por la doctrina cubana.

Al no preverse, hasta el momento, en el ordenamiento jurídico cubano, un proceso de control de constitucionalidad por vía judicial, o de amparo del derecho a la educación, la expresa prohibición de judicialización administrativa de dicho derecho constituye una seria limitación a su protección como derecho fundamental, ante posibles vulneraciones, pues faltaría para su completamiento iusfundamental la eficacia directa. Esto, además, constituiría un fuerte límite para poder vincular a la administración educativa ante decisiones restitutorias de dichos derechos.

\section{Reserva de ley}

Dicho requisito de fundamentalidad supone que las regulaciones al ejercicio de los derechos fundamentales, y como parte de ellos el derecho a la educación, deben ser decididas por el órgano de Estado con más alta legitimidad para ello: el Parlamento, o por quien ejerza la máxima función legislativa (en el caso cubano la Asamblea Nacional del Poder Popular). Sólo mediante ley se pueden configurar el alcance y los límites de los derechos fundamentales, y nunca mediante reglamento administrativo.

Esta intangibilidad legislativa garantiza una conexión relativamente directa entre la voluntad de los titulares de los derechos fundamentales y los legisladores, evitando al máximo las arbitrariedades típicas de los vaivenes políticos de los funcionarios ejecutivos electivos, o la desconexión tradicional entre los ciudadanos y los funcionarios administrativos de carrera, que acceden al cargo por concurso o designación. 
La doctrina cubana ha asumido que la reserva de ley no debe ser observada en su ordenamiento jurídico. Al respecto enuncia la profesora Martha Prieto Valdés "La Constitución cubana no tiene reservas de ley en el sentido de límites e impedimentos para el Ejecutivo, ya que la concepción unitaria sobre el poder destruye tal idea...". ${ }^{49}$ El planteamiento anterior sostiene que en un sistema sustentado en la unidad de poderes no procede observar este requisito de fundamentalidad, pues es exclusivo de la "división" de poderes.

Este autor no comparte dicho planteamiento, pues considera que hasta en los sistemas de más alta "concentración" de facultades siempre se aprecia una división y/o especialización de funciones, en que la facultad de emitir leyes se atribuye a órganos colegiados y de alta legitimidad democrática, por su conexión directa a la voluntad del soberano, de lo cual deriva la jerarquía superior de sus disposiciones; mientras que los reglamentos se reservan a quienes detentan potestades administrativas o ejecutivas, cuya legitimidad es indirecta o de segundo grado, pues son seleccionados por un órgano de representación, o simplemente designados. La reserva de ley va dirigida precisamente a evitar las decisiones usualmente unilaterales, arbitrarias o alejadas del sentir popular.

No consideramos correcto afirmar que la Constitución de la República de Cuba de 1976 carecía absolutamente del principio de reserva de ley, tampoco la recientemente aprobada Constitución de la República de 2019. Una respuesta definitiva al respecto depende de la posición que se asuma en la interpretación del párrafo final del artículo 73 de la referida Constitución.

Buscando la intención literal del Constituyente en el referido artículo, es evidente que la expresión "la ley define" se refiere a cualquier tipo de disposición normativa, emitida por cualquier órgano, sea la Asamblea Nacional, el Consejo de Estado, el Consejo de Ministros o un Ministerio. Esto supone un sentido amplio o material del término "ley".

Teniendo en cuenta la técnica legislativa en materia constitucional predominante en el proceso de creación constitucional en Cuba desde 1975, y la pretensión de las comisiones redactoras de crear un documento con la finalidad de consolidar y legitimar política e ideológicamente lo instituido,

49 Prieto Valdés, Martha, "Reflexiones en torno al carácter normativo de la Constitución”, en Pérez Hernández, Lissette y Prieto Valdés, Martha (comps.), Temas de derecho constitucional cubano, La Habana, Editorial Félix Varela, 2000, p. 31. 
y no de crear una Constitución normativa con límites al poder, ésta sería la interpretación lógica o natural. ${ }^{50}$

Contrario sensu, una interpretación evolutiva del señalado precepto justifica entender el término "ley" en su sentido estricto, ajustado a la doctrina predominante en el siglo XXI y a las necesidades, que impone al país la nueva realidad económica, política y social. Así, la "ley" sería entendida como atribución de un órgano colegiado y de alta legitimidad democrática, productor de normas de superior jerarquía por su conexión más directa a la voluntad popular. En Cuba este órgano sólo puede ser la Asamblea Nacional del Poder Popular.

Sin embargo, la realidad cubana ha sido bien distinta: no ha existido una ley general de educación que regule la materia, aunque se anuncia una propuesta para fines de 2019, estableciendo los deberes del Estado, sus obligaciones y límites, así como los derechos de los ciudadanos en cuanto al tipo de educación que desean recibir. La actividad educativa en el país, desde la promulgación de la Constitución de 1976, se ha regulado ampliamente a través de acuerdos del Consejo de Ministros, su Comité Ejecutivo, y de resoluciones de los ministerios de Educación y Educación Superior. Estas entidades ejecutivas y administrativas han dispuesto todo lo relativo al sistema nacional de educación y sus subsistemas.

Se denota una prolífera legislación tendente a asegurar un amplio acceso educativo a toda la población; pero en ese afán prestacional se ha dispuesto, en ocasiones, en contra del derecho fundamental a la educación para todos, pues no siempre se ha tenido en cuenta las particularidades de cada región, de los distintos tipos de familias, así como de las características de los aspirantes a plazas y el tipo de educación que desean recibir (laica, religiosa, especializada, generalista, etcétera). Un caso típico es la supresión de determinados tipos de escuelas especializadas en enseñanza artística en determinadas provincias, por decisión administrativa, lo que puede provocar situaciones objetivas de falta de acceso a quienes desean matricular en este tipo de enseñanza.

También se ha dado el caso de decisiones administrativas dirigidas a racionalizar recursos materiales y humanos, lo que se materializa en el cierre, fusión, traslado o desintegración de centros educativos y carreras, afectando el acceso de determinados sectores poblacionales a condiciones igualitarias de estudio o aprovechamiento educativo, así como problemas

\footnotetext{
${ }^{50}$ Idem.
} 
en la calidad del proceso docente-educativo. Estas decisiones generalmente responden a intereses gubernamentales centralizados, pero no necesariamente a exigencias de la comunidad, la región o la ciudadanía.

Esta concepción de la educación como función pública soberana del Estado se transformaría en servicio público, dirigido a satisfacer el derecho fundamental a la educación si fuera sujeta, entre otros requisitos, al principio de reserva de ley. Una materia tan trascendente como la satisfacción del derecho fundamental a la educación, debe ser configurada desde el punto de vista legislativo, en cuanto a sus alcances y límites, por el órgano de más alta legitimidad democrática del Estado. El cumplimiento del mandato popular en este sentido debe ser vinculante para los diputados del máximo órgano estatal, sin admitir regulaciones de tipo reglamentario que puedan vulnerar, restringir o de alguna manera limitar el derecho fundamental a la educación.

\section{Indisponibilidad legislativa para la regresión}

Sostiene que los derechos fundamentales siempre estarán sujetos al principio de progresión, que gozarán de una tendencia legislativa al desarrollo de nuevas garantías, nunca a una regresión en lo conquistado por la humanidad. De este planteamiento se deriva, que ninguna ley, aunque sea emitida por el Parlamento o por quien detente la función legislativa (la Asamblea Nacional del Poder Popular en Cuba), y mucho menos un reglamento administrativo, puede orientarse a debilitar las garantías iusfundamentales alcanzadas por leyes anteriores o tratados de los que el país sea Estado parte.

En el caso particular del derecho a la educación, este planteamiento supone concebir el derecho a seleccionar el tipo de educación que la persona desea, sea laica o religiosa, con la calidad óptima posible, como expresión de progresión, entendidos como garantías formales de protección ante posibles vulneraciones. Las decisiones legislativas o administrativas, de tipo organizativo, no se pueden orientar a retroceder en las conquistas alcanzadas por la legislación anterior.

En Cuba esta garantía no está claramente definida en la Constitución ni en otra disposición normativa, tampoco se puede invocar con base en ningún fallo judicial, pues no se reconoce expresamente la jurisprudencia como fuente de derecho. La situación descrita pudiera generar en la prác- 
tica la inobservancia del principio por parte de las entidades encargadas de la administración educativa, léase los ministerios de Educación y Educación Superior, o incluso por la Asamblea Nacional, el Consejo de Estado o el Consejo de Ministros. Esta situación genera un serio límite para las garantías del derecho a la educación como derecho fundamental.

\section{Contenido esencial o mínimo intocable}

Este requisito de fundamentalidad plantea que todo derecho fundamental tiene un núcleo de protección, que incluso en las situaciones más extremas no puede ser sacrificado. Como es sabido, todo derecho puede ser restringido o limitado (en dependencia de la posición teórica que sea asumida - interna o externa-) en ciertas condiciones, y bajo determinadas previsiones constitucionales. Pero incluso en esas condiciones y previsiones el contenido esencial mínimo debe respetarse, so pena que sea vulnerado el Estado de derecho. En el caso del derecho fundamental a la educación, la capacidad para leer y escribir, para superarse constantemente y con calidad en los materiales y métodos empleados, así como la libertad para escoger el tipo de educación ideológica que se desea, son condiciones inherentes al ser humano, pues forman parte de la dignidad humana, como valor iusfundamental.

Pero este criterio no es pacífico, pues en determinados contextos la doctrina y la legislación estipulan límites al propio contenido esencial o mínimo intocable. Por ejemplo, en Alemania, se alude a la "cláusula de comunidad" como excepción de aplicación del contenido esencial, mientras que en otros países como Chile no se acepta la misma. Para defender la primera postura se argumenta que “...pertenece a la esencia de los derechos fundamentales el no poder hacerlos valer cuando con ello se ponen en peligro bienes jurídicos necesarios para la existencia de la comunidad...". ${ }^{51}$

En el caso chileno, Nogueira Alcalá fundamenta lo contrario a la doctrina alemana, con base en que "...está prohibido expresamente por los tratados de derechos humanos de los que Chile es parte, y en los cuales se impone al Estado, el respeto de los derechos, aun en caso de peligro de

51 Nogueira Alcalá, Humberto, Teoría y dogmática de los derechos fundamentales, México, UNAM, Instituto de Investigaciones Jurídicas, 2003, p. 110. 
desaparición del Estado, como es en los casos de guerra interna o externa (Convención Americana de Derechos Humanos, artículo 27)". ${ }^{52}$

Ni en la Constitución cubana ni en el resto del ordenamiento jurídico existe previsión normativa que apunte al reconocimiento de un contenido esencial mínimo o intocable. Tampoco se aprecia en la doctrina patria una alusión a esta garantía, pues ha prevalecido el criterio de un poder necesariamente fuerte para enfrentar los grandes retos nacionales. Dicha justificación parece sólo aplicable a la realidad cubana, como si otras naciones que reconocen el contenido esencial o mínimo no enfrentaran retos y necesidades similares.

La previsión de un contenido esencial o mínimo intocable para el derecho a la educación es fundamental en un país sujeto a situaciones económicas impredecibles, en que las facultades administrativas en materia educacional son judicialmente incontrovertibles. No tener esta disposición garantista prevista en el ordenamiento jurídico constituye una fuerte limitación y una ausencia más para las garantías del derecho abordado.

\section{Tutela judicial efectiva}

Este requisito está estrechamente vinculado a los anteriores, y en cierta medida los integra. Plantea que los derechos fundamentales siempre podrán ser recurridos en vía judicial, pues de lo contrario no gozan de verdaderas garantías. Incluso la más plena realización material del derecho no es por sí sola una plena garantía integral, pues carece de previsión de defensa ante posibles vulneraciones. En el caso particular del derecho a la educación se concebiría como protección frente a la falta de acceso, un servicio de mala calidad, o decisiones arbitrarias de la administración educativa.

Sobre este derecho Pérez Royo plantea: "El derecho a la tutela judicial efectiva, reconocido a todas las personas y, por tanto, también a los extranjeros, comprende tres derechos: el libre acceso a los jueces y tribunales, el derecho a obtener un fallo y el derecho a la ejecución del mismo... Éste es el contenido mínimo del derecho...". ${ }^{53}$ A su vez, el referido autor encadena a esos contenidos esenciales otras garantías, que podrían llamarse instrumentales, dentro de las cuales está el derecho a un juez ordinario, a

52 Idem.

53 Pérez Royo, Javier, Curso de derecho constitucional, cit., p. 311.

Esta obra está bajo una Licencia Creative Commons

Atribución-NoComercial-SinDerivar 4.0 Internacional, IIJ-UNAM. 
asistencia letrada, a ser informado de la acusación formulada, a un proceso público sin dilaciones indebidas, proposición de pruebas, no autoincriminarse, presunción de inocencia y garantías de excusa absolutoria por parentesco y por secreto profesional.

Estas garantías instrumentales del derecho a la tutela judicial efectiva no tienen que verificarse todas para todo tipo de derechos, sino que se circunscriben a la naturaleza particular del tipo de proceso que enfrente el ciudadano o reclamante. En el caso particular de la protección a los derechos fundamentales es una garantía instrumental esencial la jurisdicción preferente y sumaria. Se debe entender que en caso de conflicto de jurisdicción debe prevalecer aquella que propenda a proteger los derechos fundamentales, o cuando en un proceso ordinario se suscite un tema de derechos fundamentales, éste debe resolverse con carácter preferente y sumario por la vía de los incidentes.

Sobre la jurisdicción preferente y sumaria para el caso de los derechos fundamentales hay posiciones encontradas: los defensores de la excepcionalidad de la acción de amparo sostienen que ésta sólo es ejercible en caso de haberse agotado previamente la vía administrativa para resolver la restitución del derecho vulnerado. Esto es interpretado como un requisito de procedibilidad.

\section{Al respecto Gregorio Badeni expresa:}

Se ha cuestionado la razonabilidad de este requisito por cuanto, si la restricción o amenaza para los derechos o garantías es real, en forma actual o inminente, y si ella proviene de un acto manifiestamente ilegal o arbitrario, no resulta atinado privar al justiciable de un remedio judicial dotado de celeridad por la sola circunstancia de que no hubiera agotado las vías administrativas previas o recurrido a los canales procesales ordinarios establecidos por la ley. ${ }^{54}$

Sin embargo, sea con obligatoriedad o no del agotamiento de la vía administrativa previa, es consenso en la doctrina que la principal garantía para la protección de los derechos fundamentales es la tutela judicial efectiva. En el caso cubano, autores como Ángel Mariño, Danelia Cutié y Josefina Méndez, sostienen que un remedio procesal indirecto ante las vulneraciones de los derechos fundamentales es la justicia administrativa.

54 Badeni, Gregorio, Tratado de derecho constitucional, Buenos Aires, La Ley, 2006, t. II, p. 1199. 
Dichos autores dudan sobre una supuesta regulación de este remedio en el artículo 26 constitucional.

Pero no tienen duda de que:

Mediante este procedimiento pueden impugnarse ante la sala de lo civil y administrativo del Tribunal Supremo Popular y de los restantes tribunales provinciales populares, todas las pretensiones que se deduzcan contra las disposiciones con carácter general y las resoluciones por los organismos de la Administración Central del Estado, sus delegaciones territoriales, así como los comités ejecutivos de los órganos provinciales y municipales del poder popular... ${ }^{55}$

Pero como se ha planteado, en Cuba, el referido artículo 657 de la Ley de Procedimiento Civil, Administrativo, Laboral y Económico prohíbe expresamente someter a proceso administrativo las cuestiones que se susciten con relación a las disposiciones que emanen de una autoridad competente, concernientes a la actividad educacional y la disciplina escolar y estudiantil. A nuestro juicio, esta es la más seria limitación que enfrenta la educación cubana para poder ser considerada un derecho fundamental de las personas y no una función pública soberana del Estado.

\section{CONCLUSIONES}

- La configuración constitucional y legal de la educación en Cuba, a partir de su prestación exclusiva y excluyente por el Estado, así como de lo incontrovertible de las decisiones administrativas en esta materia, se orienta más a una función pública soberana del Estado que a un servicio público en el sentido técnico jurídico del término. Esto ocurre independientemente de la amplia cobertura educativa que muestra el país en la actualidad.

- La falta de garantías, como la eficacia directa y vinculación de todos los "poderes" públicos, la reserva de ley, la indisponibilidad legislativa para la regresión, el contenido esencial o mínimo

55 Mariño, Ángel et al., "Reflexiones en torno a la protección de los derechos fundamentales en Cuba. Propuesta para su perfeccionamiento. Otro derecho", en Prieto Valdés, Martha y Pérez Hernández, Lissette (comps.), Selección de textos constitucionales. Primera parte, La Habana, ENPSES, 1994, p. 94. 
intocable, además de la tutela judicial efectiva, constituyen serias limitaciones para considerar la educación en Cuba como un derecho fundamental. Esta situación legislativa puede ubicar a los titulares del derecho en posiciones de desprotección ante posibles vulneraciones emanadas de arbitrariedades administrativas o de retrocesos legislativos.

\section{BIBLIOGRAFÍA}

ABRAmovich, V. y Curtis, C., Los derechos sociales como derechos exigibles, 2a. ed., Madrid, Trotta, 2004.

AleXY, Robert, Teoría de los derechos fundamentales, Madrid, Centro de Estudios Constitucionales, 1993.

BADENI, Gregorio, Tratado de derecho constitucional, Buenos Aires, La Ley, 2006, t. II.

Bell LaRA, José et al., Documentos de la Revolución Cubana 1961, La Habana, Editorial de Ciencias Sociales, 2008.

CARBonell, Miguel y Ferrer MAC-GREGor, Eduardo, Los derechos sociales y su justiciabilidad directa, México, Flores Editor y Distribuidor, 2014.

CASAL, Jesús María, Constitución y justicia constitucional. Los fundamentos de la justicia constitucional en la nueva carta magna, Caracas, $\mathrm{Pu}-$ blicaciones UCAB, 2000.

Ferrajoli, Luigi, Derechos y garantias. La ley del más débil, Madrid, Trotta, 2004.

GonZÁlez Monguí, Pablo Elías (coord.), Derechos económicos, sociales y culturales, Bogotá, Kimpres Ltda., 2009.

LÓPEZ Guerra, Luis et al., Derecho constitucional, vol. I. El ordenamiento constitucional. Derechos y deberes de los ciudadanos, Valencia, Tirant lo Blanch, 2000.

MARIÑO, Ángel et al., "Reflexiones en torno a la protección de los derechos fundamentales en Cuba. Propuesta para su perfeccionamiento. Otro derecho", en PRIETo VAldés, Martha y PÉREZ Hernández, Lissette, Selección de textos constitucionales, Primera parte, La Habana, ENPSES, 1994. 
Nogueira AlCAlÁ, Humberto, Teoría y dogmática de los derechos fundamentales, México, UNAM, 2003.

PAHUAmBa Rosas, Baltazar y ZaVAla GALLARDO, Erick (coords.), Aplicación de los derechos humanos, México, Liber Iuris Novum, 2014.

PARADA VÁZQUEZ, Ramón, Derecho administrativo I, parte general, Madrid, Marcial Pons, 1991.

PÉREZ LuÑo, Antonio Enrique, Los derechos fundamentales, Madrid, Tecnos, 1994.

PÉREZ Royo, Javier, Curso de derecho constitucional, Madrid, Marcial Pons, 1997.

PRIETO VAldÉS, Martha, "En pos de la aplicabilidad directa de la Constitución cubana de 1976 (un breve comentario), IUS Revista del Instituto de Ciencias Jurídicas de Puebla, (21), 2008.

PRIETO VALDÉS, Martha, "Reflexiones en torno al carácter normativo de la Constitución”, en PÉrez Hernández, Lissette y PRIETO VALdÉs, Martha, Temas de derecho constitucional cubano, La Habana, Editorial Félix Varela, 2000.

SANTAMARÍA PASTOR, Juan Alfonso, Principios de derecho administrativo general II, Madrid, Iustel, 2009.

Villabella ARMENGol, Carlos Manuel, "Los derechos humanos. Consideraciones teóricas de su legitimación en la Constitución cubana", en Prieto Valdés, Martha, Selección de textos constitucionales, Primera parte, La Habana, ENPSES, 1991.

Fecha de recepción: 14 de mayo de 2018.

Fecha de aceptación: 12 de marzo de 2019.

Esta obra está bajo una Licencia Creative Commons

Atribución-NoComercial-SinDerivar 4.0 Internacional, IIJ-UNAM. 